\title{
Technical Advances in Precision Farming
}

\author{
Ramkrishna \\ Vadali \\ Assistant Professor, \\ Pimpri Chinchwad \\ College of \\ Engineering, Nigdi, \\ Pune
}

\author{
Swati Sakhare \\ Student \\ Pimpri Chinchwad \\ College of \\ Engineering, Nigdi, \\ Pune
}

\author{
Jayshri Patil \\ Student \\ Pimpri Chinchwad \\ College of \\ Engineering, Nigdi, \\ Pune
}

\author{
Sonali Nale \\ Student \\ Pimpri Chinchwad \\ College of \\ Engineering, Nigdi, \\ Pune
}

\begin{abstract}
In the agriculture field, use of perfect method of irrigation is important as well as it is known by everyone that irrigation by drip method is very economical and efficient as well as widely acceptable. Agriculture plays vital role in the development of agricultural country. The newly come up wireless sensor network (WSN) technology has spreading rapidly into distinct fields. Agriculture and farming is one of the management which have freshly switch their consideration to WSN, searching this cost adequate technology to improve its production and boost agriculture yield standard. The scope of this paper is to design and develop an agricultural monitoring system using wireless sensor network and IoT to expand the productivity and quality of farming without penetrating it for all the time manually. Temperature, humidity and water levels are the most important factors for the productivity, growth, and quality of plants in agriculture. The temperature, humidity and water level sensors are deployed to gather the temperature and humidity values. One of the most stimulating fields having an exotic need of Decision Support System (DSS) is Precision Agriculture (PA). Through sensor networks, agriculture can be connected to the IoT, with the help of this approach which provides real-time information about the lands and crops that will help farmers make right decisions. The primary influence is implementation of WSN in Precision Agriculture (PA) with the help of IoT which will enhance the usage of water, fertilizers while expand the yield of the crops and also notifications are sent to farmers mobile periodically. The farmers can able to monitor the field conditions from anywhere.
\end{abstract}

\section{Keywords}

Internet of Things (IoT), Wireless sensor Network (WSN), Precision Agriculture (PA), Decision Support System (DSS), Smart Device, Automation.

\section{INTRODUCTION}

India is agriculture oriented country, $70 \%$ of Indian population has agriculture as their main occupation or side business. The production or cultivation of useful crops in the Ecosystem produced by the people is known as agriculture. Nowadays agriculture has changing through considerable innovation in terms of using technology in agriculture techniques. The first technology to agriculture was of the tractor. It proved to be more efficient and helpful machine to the farmers. In agriculture irrigation is the important factor as the monsoon rainfalls are unpredictable and uncertain. Agriculture in the face of water scarcity has been a big challenge [1].

There are varieties of traditional irrigation systems that have been followed from the past. For instance, in flow irrigation the water resources like tanks or reservoirs are placed at great heights. The water starts to flow automatically down the channel when it is connected to the tank or reservoir. This type of irrigation methods are mostly used in plain areas [3]. The other type of irrigation is lift irrigation where the fields are at higher level than the water resources. The land is irrigated by lifting water from wells, tanks, canals, rivers using pumps. Nowadays the ground water is also pumped to irrigate the land.

The up-gradation in the technology will help farmers to raise the crop gain. The new approach in the technologies are (i)Internet of Things (IoT) (ii)Wireless Sensor Network (WSN) (iii)Precision Agriculture (PA) (iv)Decision Support System (DSS). The internet of things is the network in which the real world objects are associated to each other which influence to form many embedded system including fields such as electronics and sensors through which the data can be relocated and received reliably.

A paper proposed an irrigation system management which is used to utilize water in effective way for agriculture using wireless GSM technology. It includes a mobile application which is connected to IoT system through GSM. A motor pump which is used to lift the water from wells, canals, rivers, we have to analyze the motor pump specification, because how much time take by motor pump to lift quantity of water from particular source of water. Wireless sensors which are used for collection of data such as humidity, soil moisture, this information display on mobile. Depending on that information how much water require irrigating that land, only for a particular time motor pump will be ON by farmers. So water is used efficiently in draught conditions also.

\section{LITERATURE SURVE}

Presently there is an urgent need of proper utilization of water because of drying up of rivers and tanks. To cope up with this use of temperature and moisture sensor at suitable locations for monitoring of crops is implemented [4]. The new, advanced innovative development in Wireless Sensor Networks made it possible to use in monitoring and control of all the environment related greenhouse parameter in precision agriculture [1].

Wireless sensor network (WSN) and Wireless Moisture Sensor Network (WMSN) are components of IoT. Proper irrigation system could be achieved by using WSN technology. Monitoring and control applications have been tremendously improved by using WSN technology. It enabled efficient communication with many sensors. WMSN is a WSN with moisture sensors. The precision agriculture is a decision support system (DSS) that acquires data from various sources, analyzes them, and recommends actions. DSS to control various field devices through unified software defined interfaces 
[2]. Various systems have been developed that are being controlled by using GSM.

However, use of technology in the field of agriculture plays important role in increasing the production as well as in reducing the extra man power efforts. Some of the research attempts are done for betterment of farmers which provides the systems that use technologies helpful for increasing the agricultural yield. In the studies related to wireless sensor network, researchers measured soil related parameters such as temperature and humidity. Sensors were placed below the soil which communicates with relay nodes by the use of effective communication protocol providing very low duty cycle and hence increasing the life time of soil monitoring system [5]. The whole system was advance using various terminologies in field sensor terminal which collects the data and send it to the base terminal that is default server where necessary activity was taken for regulating irrigation according to the database available with the system. The system contributes an encouraging low cost wireless solution as well as remote controlling for precision framing along with irrigation system [6].

\section{PROPOSED SYSTEM}

For development of our system we have to require Wireless sensor network, Smart phone, hardware, and microcontroller. A WSN i.e. Wireless sensor network is a distributed sensor network to monitor physical or environmental conditions, such as temperature, humidity and moisture to cooperatively pass their data through the network to a main location. We have to implement various types of sensors such as soil moisture, temperature, humidity etc. Information is the parameters of the soil and the parameters of theweather for each specific location. Based of those information correct irrigation could be planed.

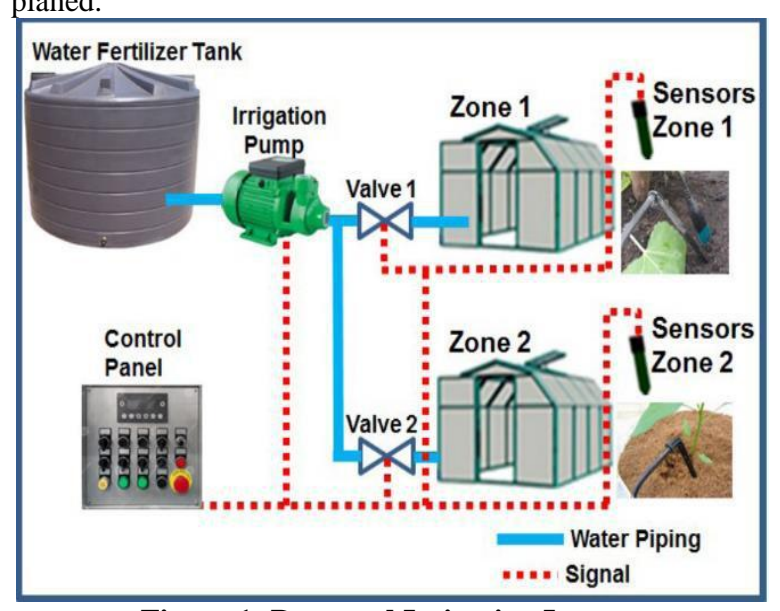

Figure 1: Proposed Irrigation Layout

Figure 1 shows the layout basic irrigation system Architecture. The system manages and optimizes all the input and output. The moisture sensor reading is an input data and transmitted to control panel wirelessly using based wireless sensor network (WSN) technology. Temperature, humidity and moisture sensor are used. Data which is collected from this sensor are sent to a server for analyzing and monitoring purpose. Threshold value are already set up or programmed into the microcontroller chip (8051).

Drip Irrigation is a technique in which water flows through a filter into special drip pipes, with emitters located at different spaces or gives the water. In this, Drip Irrigation system proposes completely automated system which reduces human efforts. In this system automation in irrigation can be achieved with the help of different sensors and raspberry Pi. The purpose of system is to give the indication to the farmer and then farmer will ON or OFF water supply. The different sensors like humidity, temperature, soil moisture will be deployed in the field to monitor the environmental conditions. We have to analyze how much water lift by the motor pump or irrigation pump in particular time period. For that purpose we are going to develop a mobile application which is installed on smartphone. GSM service is used in between smartphone and microcontroller. From mobile phone farmers are able to start or stop the irrigation pump. Depends on irrigation pump specification how much quantity of water lifted by pump in particular time. Based on that farmer can be start their irrigation pump for particular amount of time. It save water and reduce human intervention in the agriculture field.

We are going to design an input device which can take input of Environmental condition. We can take input from sensors and store that data into file. Based on the sensor information, indication should begiven to the farmers through mobile SMS system. The main objective of this system is to save water and reduce human intervention in the agriculture field. Continuously monitoring the status of sensors and provide signal for taking necessary action. It get the input of soil moisture and provide output that is provide water to crop. To observed other parameter for better yield.

\section{METHODOLOGY 4.1 IOT (Internet Of Things)}

The Internet of things (IoT) is the network of physical devices, vehicles, home appliances embedded with electronics, software, sensors, actuato rs, and network connectivity which enable these objects to connect and exchange data. The IoT enabled objects to be sensed and/or controlled remotely across previously network infrastructure, creating opportunities for more direct integration of the physical world into computerbased systems, and appearing in improved efficiency, accuracy and economic asset. Experts estimate that the IoT will consist of almost 50 billion objects by 2020 .

\subsection{Wireless Sensor Network}

A sensor is a device that recognize and responds to some type of input from the physical environment. The specific input could be light, heat, motion, moisture, pressure, or any one of a great number of other environmental phenomena. The output is generally a signal that is converted to human-readable display at the sensor location or transmitted electronically over a network for reading or further processing. A WSN is a distributed sensor network to monitor physical or environmental conditions, such as temperature, humidity and moisture to cooperatively pass their data through the network to a main location.

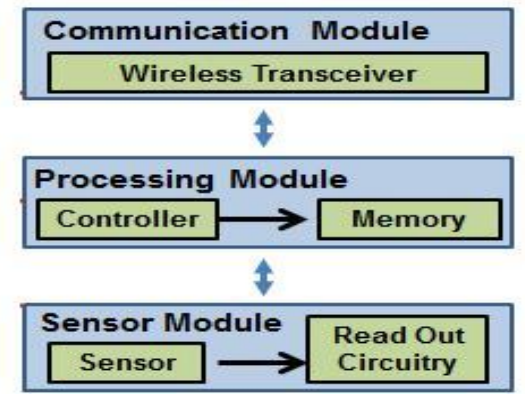

Figure 2: Different modules of sensor 
Shown in figure- 2 which is for routing purpose and for gateway purpose, graphical user interface (GUI) for visual inspection or manual user interaction, power source, sensors for capturing sensing parameters. Most important sensors for this project are moisture sensors. Temperature sensor can measure temperature more accurately than a using a thermostat. Humidity is an integrated circuit sensor that can be used to measure the presence of water in land. Water level floats sensor, also known as float balls, are spherical, cylindrical, belong or similarly shaped objects, made from either rigid or flexible material, that are buoyant in water and other liquids. They are non-electrical hardware again and again used as visual sight-indicators for surface separation and level evaluation. They may also be incorporated into switch mechanisms or translucent fluid-tubes as a component in monitoring or controlling liquid level.

\subsection{Soil Moisture Sensors}

In Precision Agriculture (PA), one of the important sensors is moisture sensor. Moisture sensor would provide level of water in the soil. Level of water for specific crops is determined by agronomist. Based on the water level feedback system would have a knowledge on how much water need to irrigate the crops. Too much water in the soil would affect the usage of Nitrogen of the roots. At the same time the Oxygen at the roots will be insufficient. Each type of crops would require various level of water. As such level of water indicate by moisture would be different depend on the type of crops.

\subsection{Data Processing and Decision Making}

The data received from the field are wirelessly transmitted and then saved in server database using connection at receiver end. Periodically the data are received and stored in database. The data processing is the task of checking the various sensors data received from the field with the already fixed threshold values. The threshold values vary according to the crops planted. This is because different crops need different amounts of water. The sensor values also vary according to the climatic conditions. The soil moisture will be different in summer and winter Season. The temperature and humidity also varies in summer, winter and rainy season. The threshold values are fixed after considering all these environmental and climatic conditions. The motor will be switched on automatically if the soil moisture value falls below the threshold and vice versa. The Farmer can even switch on the motor from mobile using mobile application.

A wireless sensor network in general consist of processing component, communication components

\subsection{Automation of Irrigation System}

The irrigation system is automated once the control is received from the web application or mobile application. The relays are used to pass control from web application to the electrical switches using Raspberry pi. A relay is an electrically operated switch. The circuits with low power signal can be controlled using relay. There different types of Relays which includes reed relay, solid state relays and protective relay etc. The relay used here is Solid State Relay (SSR). Different types of sensors (temperature, humidity and water level) used for agriculture monitoring and crops production. The system will beneficial and works in cost effective manner. It reduces the water consumption to a greater extent. The System is very useful in areas where water scarcity is a major problem. The crop productivity increases and the wastage of water is very much reduced using this irrigation system.

\section{CONCLUSION}

This paper presents a crop irrigation system based on wireless sensor network. Implementation of such a system in the field can definitely help to improve the yield of the crops and overall production. IoT has important significance in promoting agricultural information. This method can use to reduce human interaction in agriculture field. Drip irrigation helps to water conservation along with useful utilization of water.

Along with, this also supports Prime Minister's Digital India Program. It includes farmers can learn new, advance technologies in farming system. This helps them to increase their digital enrollment and increase automation in agriculture field.

\section{REFERENCES}

[1] Joaquín Gutiérrez, Juan Francisco Villa-Medina, Alejandra Nieto-Garibay, and Miguel Ángel PortaGándara" Automated Irrigation System Using a Wireless Sensor Network and GPRS module", IEEETransactions On Instrumentation And Measurement, Vol. 63, No. 1, January 2014.

[2] Li Tan, Hongfei Hou, Qin Zhang “An ExtensibleSoftware Platform for Cloud-based Decisio Support and Automation in Precision Agriculture" 2016 IEEE 17th International Conference on Information Reuse and Integration.

[3] Ibrahim Mat, Mohamed Rawidean Mohd Kassim, Ahmad Nizar Harun, "Precision Agriculture Applications using Wireless Moisture Sensor Network," 2015 IEEE 12th Malaysia International Conference on Communications (MICC), Kuching, Malaysia (23 - 25 Nov 2015).

[4] Ashwini Raut, Mrunal Panse, Darshana Chaware, Aniruddha Koparkar "Sensor Based Automated Irrigation system", International Journal of Engineering Research \& Technology, ISSN: 2278-0181, Vol. 4 Issue 05, May-2015.

[5] S. R. Nandurkar, V. R. Thool, R. C. Thool,"Design and Development of Precision Agriculture System Using Wireless Sensor Network",IEEE International Conference on Automation, Control, Energy and Systems (ACES), 2014

[6] Y. Kim, R. Evans and W Iversen, "RemoteSensing and Control of an Irrigation System Using aDistributed Wireless Sensor Network", IEEE Transactions on Instrumentation and Measurement, pp. 1379-1387, 2008.

[7] Rashid Hussain, JL Sahgal, Anshulgangwar, Md. Riyaj, "Control of Irrigation Automatically By Using Wireless Sensor Network" International Journal ofSoft Computing and Engineering (IJSCE) ISSN:2231-2307, Volume-3, Issue-1, March 2013. 